\title{
Predictive indicators for revisional surgery in nasal reconstruction after Mohs surgery
}

\author{
Tom W. Andrew ${ }^{1}$ (D) Jennifer J. Garioch ${ }^{2,3} \cdot$ Penny E. Lovat ${ }^{4} \cdot$ Marc D. Moncrieff $^{3}$ \\ Received: 1 September 2020 / Accepted: 8 October 2020 / Published online: 10 November 2020 \\ (C) The Author(s) 2020
}

\begin{abstract}
Background Reconstruction of nasal lesions is complex due to the topography, mobile free margins and borders of anatomical subunits. Reconstructive challenges can lead to multiple revisional surgeries to achieve the final aesthetic result. This study aimed to evaluate risk factors and predictors of revisional surgery in patients undergoing reconstruction after Mohs micrographic surgery for nasal tumours.

Methods This was a prospective cohort study from April 2, 2008 to February 26, 2019. The study population included all consecutive patients who underwent Mohs micrographic surgery for nasal skin cancer. Resection and reconstruction of nasal skin cancer was performed by the Mohs team.

Results A total of 988 cases met our study inclusion criteria with 64 (6.5\%) cases requiring unplanned surgical revision. Revision rates were highest in the ala $(9.0 \%, p<0.05)$ and complex anatomical subunits $(16.7 \%, p<0.0001)$. In contrast, revision rates for dorsum lesions were lowest $(1.8 \%, p<0.001)$. In terms of reconstructive modalities, local flaps resulted in significantly higher rates of revision when compared to grafts (relative risk, 2.37 ; $95 \% \mathrm{CI}, 1.15-5.0 ; p<0.01$ ). In terms of histological diagnosis, squamous cell carcinoma had significantly higher revision rates when compared to basal cell carcinoma $(p<0.05)$.

Conclusions To our knowledge, this is the first study to report the risk factors and predictors of revision surgery in patients undergoing MMS for nasal tumours. This study highlights that the reconstructive modality utilised affects the functional and cosmetic outcome of MMS. We note that ala complex subunit lesions, squamous cell carcinoma and flap reconstruction were associated with an increased risk of revision after Mohs reconstruction of nasal lesions.

Level of evidence: Level III, risk/prognostic; therapeutic study.

Trial registration number (Ref: PLA-19-20_A03) 04/02/2020.
\end{abstract}

Keywords Revision $\cdot$ Nose $\cdot$ Nasal $\cdot$ Mohs $\cdot$ Reconstruction $\cdot$ Prediction $\cdot$ Risk $\cdot$ Complications $\cdot \mathrm{BCC} \cdot \mathrm{SCC} \cdot \mathrm{Melanoma}$

Tom W. Andrew

Tom.Andrew@ncl.ac.uk

1 Department of Plastic and Reconstructive Surgery, Norfolk and Norwich University Hospital NHS Foundation Trust, Norwich NR4 7UY, UK

2 Department of Dermatology, Norfolk and Norwich University Hospital NHS Foundation Trust, Norwich NR4 7UY, UK

3 Norwich Medical School, University of East Anglia, Norwich, UK

4 Translational and Clinical Research Institute, Newcastle University, Newcastle NE2 4HH, UK

\section{Introduction}

Mohs' micrographic surgery (MMS) has been increasingly used in head and neck cutaneous oncology to minimise the excisional defect by providing the most accurate method of intraoperative histological assessment of tumour margins [1]. The British Association of Dermatologists recommend the use of MMS primarily for complex skin cancers where confirmation of complete clearance is paramount prior to reconstruction; complex cancers includes those of high-risk anatomical site, such as the nose [2]. MMS leads to significantly fewer recurrences when compared to simple surgical excision as specimens are flattened and sliced horizontally, offering examination of up to $100 \%$ of resection margins [3-5]. Micrographic excision of nasal lesions typically produces defects that require surgical reconstruction [6]. 
The nose is in the centre of the face and is highly heterogeneous in colour, texture and topography $[7,8]$. To achieve optimal aesthetic and functional outcomes, the surgeon must consider a range of reconstructive options, depending on the dimensions of the excisional defect, the structure of the resected tissues and the involved aesthetic nasal subunit [9]. According to Burget and Menick [9], optimum aesthetic results require excision of the entire involved subunit. This has been challenged by Rohrich and colleagues [10], suggesting to minimise resection of healthy tissues with reconstruction of the defect and not the entire subunit. They recommend complementary procedures to enhance aesthetic outcome. Improvements in analysis and planning combined with higher standards for aesthetic results have resulted in the trend toward an increased number of procedures [11]. In addition, multiple staged procedures are often used to complete the sequence and achieve the final aesthetic result $[9,10,12,13]$.

The aim of this project was to guide dermatological and reconstructive surgeons and improve patient outcomes by analysis of data from our prospectively collected cohort of patients undergoing MMS to their nasal tumours in order to advance the understanding, management and improve the outcomes of patient care by identifying risk factors and predictors for revision surgery. We also aimed to provide data that may guide the reconstructive surgeon about service planning for patients undergoing Mohs resection for skin cancer.

\section{Patients and methods}

This study was approved by the Clinical Audit and Improvement Department at the Norfolk and Norwich University Hospital (Ref: PLA-19-20_A03). The study population included all consecutive patients who underwent Mohs micrographic surgery for nasal skin cancer between April 2, 2008 and February 26, 2019. Resection and reconstruction of nasal skin cancer were performed by the Mohs team (either a dermatologist or plastic surgeon) at the Norfolk and Norwich University Hospital Skin Tumour Unit. Treatment and outcomes of nasal reconstruction following Mohs surgery were obtained. The patient demographics and intraoperative data were obtained from the electronic patient notes and electronic theatre records. Histological data were acquired from the electronic patient notes. Follow-up data were entered from the electronic patient notes. Nasal skin cancer lesions were defined by anatomical subunit: medial canthus $(n=119)$, ala $(n=312)$, columella $(n=5)$, dorsum $(n=243)$, complex (tumour involved more than one nasal subunit at the time of diagnosis) $(n=90)$ and tip $(n=219)$. One patient was excluded due to incomplete documentation.

We conducted analyses for gender, age, anatomical location, histological diagnosis, reconstructive modalities and surgical revision. All analyses were performed using Excel 15.0

(Microsoft Corporation, Redmond, WA) and GraphPad Prism version 8.0.0 (GraphPad Software, Inc., San Diego, CA). Chisquared and Fisher's exact test were used to identify statistically significant associated risk factors for surgical revision. Fisher's exact test was used for replicates of $\leq 5$; otherwise, chi-squared was used. In addition, unpaired $T$ test and relative risk ratio were used to analyse age and sex respectively.

\section{Results}

A total of 988 cases met our inclusion criteria for the study. Table 1 describes the patient demographic data. The group had a mean age of 67 (SD, 12 years; range, 18 to 89 years) at the time of removal of nasal skin malignancy. The cohort consisted of $426(43.1 \%)$ males and $562(56.9 \%)$ females.

The distribution of nasal tumours according to anatomical subunit is outlined in Table 1. The most frequent location was the nasal ala (32\%), followed by the dorsum (25\%), tip (22\%), medial canthus (12\%) and columella (1\%). In 90 cases (9\%), the tumour involved more than one nasal subunit at the time of diagnosis (nasal complex). Basal cell carcinoma represented $930(94 \%)$ of the cutaneous lesions compared to $38(4 \%)$ cases of squamous cell carcinoma (Table 2). The prevalence of basal cell carcinoma is significantly greater in the ala region when compared to other subunits $(p<0.05)$. In contrast, squamous cell carcinoma is significantly more prevalent in nasal complex tumours when compared to tumours contained to a single subunit $(p<0.0001)$.

As shown in Table 3, results show that the most commonly utilised reconstructive modality was a local flap (540 patients), followed by skin graft (277 patients), primary closure

Table 1 Patient and defect characteristics

\begin{tabular}{ll}
\hline Characteristic & Finding \\
\hline Patient characteristics & \\
Age, years & \\
Mean (SD) & $67(12)$ \\
Median (range) & $69(18-89)$ \\
Sex & \\
Male & $426(43.12 \%)$ \\
Female & $527(56.895 \%)$ \\
Defect characteristics $(n=988)$ \\
Location-nose & \\
Medial canthus & $119(12.04 \%)$ \\
Ala & $312(31.58 \%)$ \\
Collumella & $5(0.51 \%)$ \\
Dorsum & $243(24.60 \%)$ \\
Complex & $90(9.11 \%)$ \\
Tip & $219(22.17 \%)$ \\
\hline$S D$, standard deviation &
\end{tabular}


Table 2 Histology and location

\begin{tabular}{|c|c|c|c|}
\hline \multicolumn{2}{|c|}{ Histology and location } & \multicolumn{2}{|c|}{ No. $(\%)$} \\
\hline \multicolumn{4}{|l|}{ Histology $(n=988)$} \\
\hline \multicolumn{2}{|c|}{ Basal cell carcinoma } & \multicolumn{2}{|c|}{$930(94.13 \%)$} \\
\hline \multicolumn{2}{|c|}{ Squamous cell carcinoma } & \multicolumn{2}{|c|}{$38(3.85 \%)$} \\
\hline \multicolumn{2}{|l|}{ Other } & \multicolumn{2}{|c|}{$19(1.92 \%)$} \\
\hline \multicolumn{2}{|l|}{ Unknown } & \multicolumn{2}{|c|}{$1(0.10 \%)$} \\
\hline Location $(n=988)$ & $\mathrm{BCC}$ & $\mathrm{SCC}$ & $p$ value \\
\hline Medial canthus & 110 & 6 & 0.2306 \\
\hline Ala & 303 & 7 & $0.0333 *$ \\
\hline Columella & 4 & 1 & $0.0318^{*}(\mathrm{FE})$ \\
\hline Dorsum & 231 & 6 & 0.1818 \\
\hline Complex & 73 & 11 & $<0.0001 * * * *$ \\
\hline Tip & 209 & 38 & 0.2783 \\
\hline
\end{tabular}

$B C C$, basal cell carcinoma; $F E$, Fisher exact test; $S C C$, squamous cell carcinoma

$*=p<0.05$

$* * * *=p<0.0001$

(69 patients), secondary intention (39 patients), flap and cartilage graft (16 patients), flap and graft (13 patients), free tissue transfer (6 patients) and prosthesis (1 patient). Local flaps were the most frequently used reconstructive modality for all subunits, except for the columella, which were most often reconstructed with skin grafting. Cutaneous lesions of the nasal dorsum were more frequently closed primarily when compared to other subunits $(p<0.0001)$.

There were $64(6.5 \%)$ cases requiring unplanned surgical revision (Table 4). Revision rates according to anatomical subunit were medial canthus, 8 (6.7\%); ala, $28(9.0 \%$, $p<0.05)$; columella, 0 (0\%); dorsum, 4 (1.8\%, $p<0.001)$; complex, $15(16.7 \%, p<0.0001)$ and tip, $9(4.11 \%)$ (Table 4). Revisions were also stratified by reconstructive modality. Local flaps resulted in significantly higher rate of revision when compared to grafts (relative risk, 2.37; 95\% CI,
$1.15-5.0 ; p<0.01$ ) (Table 4). This was also true when comparing all anatomical subunits collectively, as well as isolated ala lesions $(p<0.05)$. Squamous cell carcinoma was associated with significantly higher revision rates when compared to basal cell carcinoma $(p<0.05)$. There was no statistical difference between sex (relative risk 1.093; 95\% CI, 0.682-1.75; $p=0.357)$ and age $(p=0.6551)$ between patients who did and did not require unplanned surgical revision.

\section{Discussion}

In this prospective cohort of patients requiring nasal reconstruction after MMS tumour resection, we investigated the variables associated with unplanned surgical revision and determined which characteristics were associated with higher revision rates. Surgical revision was defined as those cases which required unplanned operative revision. We observed a revision rate of $6.5 \%$, which varied from 0 to $16.7 \%$ according to the anatomical location of the tumour. This was comparable to the literature involving complications of facial lesions, $6.69 \%$ [14]. In this study population, the incidence of surgical complication is higher in nasal lesions [14, 15]. The mean age of patients requiring surgical revision was 66 years, compared to 67 years in the group without revision. We also identified that gender had no influence on revision rates with $45 \%$ of revision cases being male, compared to $43 \%$ in non-revision cases.

Tumour dimensions in the lower third of the nose are not representative where lesions can cover multiple subsections of anatomical subunits [9]. Anatomical subunits are a more sophisticated measure of tumour burden when compared to tumour dimensions [10]. We have therefore defined tumour burden by anatomical subunit. This cohort, to our knowledge, is the first of sufficient size to document an association between anatomical subunit location and surgical revision. Most cancers involved the ala, dorsum and nasal tip, as observed by Rohrich et al. [10]. We
Table 3 Reconstructive modality and tumour location

\begin{tabular}{llllllll}
\hline $\begin{array}{l}\text { Reconstructive modality } \\
(n=988)\end{array}$ & $\begin{array}{l}\text { Medial } \\
\text { canthus }\end{array}$ & Ala & Columella & Dorsum & Complex & Tip & Total \\
\hline Local flap & 37 & $234^{*}$ & 1 & 110 & $31^{*}$ & $127^{*}$ & $540^{*}$ \\
Graft & $50^{*}$ & 48 & 2 & 85 & 27 & 65 & 277 \\
Direct closure & 13 & 4 & 1 & $36^{* * * *}$ & 9 & 6 & 69 \\
Secondary Intention & 13 & 8 & 0 & 5 & 7 & 6 & 39 \\
Free-flap & 0 & 0 & 1 & 1 & 6 & 1 & 9 \\
Flap and graft & 3 & 6 & 0 & 0 & 2 & 2 & 13 \\
Flap and cartilage & 0 & 9 & 0 & 3 & 1 & 3 & 16 \\
Prosthesis & 0 & 0 & 0 & 0 & 1 & 0 & 1 \\
Incomplete documentation & 119 & 312 & 5 & 243 & 90 & 219 & 988 \\
\hline
\end{tabular}

$*=p<0.05$

$* * * *=p<0.0001$ 
Table 4 Revision rate-based potential risk factors

\begin{tabular}{|c|c|c|c|}
\hline Revision rates $(n=988)$ & & No. $(\%)$ & \\
\hline Revision surgery & & $64(6.48 \%)$ & \\
\hline No revision surgery & & $924(93.52 \%)$ & \\
\hline Location $(n=988)$ & Revision surgery & No revision surgery & $p$ value \\
\hline Medial canthus & 8 & 111 & 0.4539 \\
\hline Ala & 28 & 284 & $0.0152 *$ \\
\hline Columella & 0 & 5 & 0.2776 \\
\hline Dorsum & 4 & 239 & $0.0002 * * *$ \\
\hline Complex & 15 & 75 & $<0.0001 * * * *$ \\
\hline Tip & 9 & 210 & 0.0533 \\
\hline Histology $(n=988)$ & Revision surgery & No revision surgery & $p$ value \\
\hline Basal cell carcinoma & 57 & 873 & $0.0414 *$ \\
\hline Squamous cell carcinoma & 5 & 33 & \\
\hline Reconstructive modality & Revision surgery & No revision surgery & $p$ value \\
\hline All & 45 & 772 & \\
\hline Flap & 37 & 503 & $0.0094 * *$ \\
\hline Graft & 8 & 269 & \\
\hline Medial canthus & 6 & 81 & \\
\hline Flap & 4 & 33 & 0.1076 \\
\hline Graft & 2 & 48 & \\
\hline Ala & 25 & 257 & \\
\hline Flap & 24 & 210 & $0.0348 *$ \\
\hline Graft & 1 & 47 & \\
\hline Dorsum & 2 & 193 & \\
\hline Flap & 1 & 109 & $0.1838(\mathrm{FE})$ \\
\hline Graft & 1 & 84 & \\
\hline Complex & 7 & 51 & \\
\hline Flap & 4 & 27 & 0.4172 \\
\hline Graf & 3 & 24 & \\
\hline Tip & 4 & 188 & \\
\hline Flap & 4 & 123 & 0.0741 \\
\hline Graft & 0 & 65 & \\
\hline Sex & Revision surgery & No revision surgery & $p$ value \\
\hline Male & 29 & 397 & 0.3667 \\
\hline Female & 35 & 527 & \\
\hline \multirow[t]{2}{*}{ Age, years } & Revision surgery & No revision surgery & $p$ value \\
\hline & 66.68 & 67.32 & 0.6551 \\
\hline
\end{tabular}

$F E$, Fisher exact test.

$*=p<0.05$

$* *=p<0.01$

$* * *=p<0.001$

$* * * *=p<0.0001$

observed a significantly increased revision rates in the alar subunit. We propose that this is due to the clinical challenges of alar subunit reconstruction. The alar cartilages provide the support of the lower third of the nose [7]. Zitelli [16] reported retraction and protraction of the alar margin in alar subunit reconstruction, which can be minimised with an appropriately designed bilobed flap. Alternatively, the dorsal nasal flap [17], reportedly creates less deformity at the dorsum and nasal tip when compared to the bilobed flap. Despite this, it can produce upward rotation of the nasal tip and alar rim retraction [10]. Lateral alar defects can be reconstructed using a nasolabial flap; however, subsequent revision is not uncommon due to nasofacial angle blunting at the pedicle of the flap. In addition, we have identified that complex nasal defects have an increased risk of surgical revision. We define complex nasal defects as involving multiple nasal subunits; these are intrinsically larger in size and often require more intricate reconstruction. Similarly, Patel et al. observed that complex facial defects are significantly associated with post-operative complications, including the need for revision [18].

In contrast to other anatomical subunits, we observed reduced revision rates in dorsal nasal lesions. In this group, primary closure was utilised more frequently as a reconstructive modality. We hypothesise that as direct closure is often limited to small defects but [7], in part, the relative laxity and mobility of the skin in this area lend itself better to simple closure procedures. The reduced incidence of revision in dorsal lesions is due either to smaller dimensions or due to an inherent reduction in post-operative complications in nasal lesions reconstructed with primary closure.

We observed that squamous cell carcinoma was associated with higher rates of revision compared to basal cell carcinoma. To our knowledge, this is the first study to identify squamous 
cell carcinoma as predictor for revisional surgery in nasal cancers. Squamous cell carcinoma often extends through the skin to the mucosa by deep invasion requiring a greater number of layers for complete excision when compared to BCC lesions. In addition, squamous cell carcinomas are often larger, thereby involving multiple subunits when compared to basal cell carcinomas. Nasal structural support as well as mucosal lining have optimised to provide a successful outcome of composite nasal reconstruction [19]. Squamous cell carcinoma often involves multiple anatomical subunits when compared to basal cell carcinoma, demonstrating more extensive disease progression. Basal cell carcinoma in contrast has demonstrated low levels of recurrence over a 5-year period when MMS has been utilised [14].

In this study, we demonstrate significant differences in revision rates according to the reconstructive modality utilised. We observed significantly fewer revisions in graft reconstruction compared to flap reconstruction. Skin grafting has been described as a good reconstructive option for resections limited to small amounts of subcutaneous tissue, particularly in elderly patients [9]. In contrast, local flaps use adjacent tissues to provide an advantageous colour and contour match [10, 20]. Flaps have been shown to have improved aesthetic outcomes in nasal reconstruction when compared to skin grafts, as a result, there has been paradigm shift toward their use [10]. We found that local flaps were associated with an increased risk of revision. Local flap reconstruction is often restricted for larger defects which intrinsically have an increased proportion of preoperative bone or cartilage exposure. Newlove and Cook [21] had similar findings with respect to the complication rates of flaps, who concluded that flap repair is associated with a higher rate of complications. Pedicled forehead flaps are routinely used for excisional defects larger than $1.5 \mathrm{~cm}$ in diameter [10], or those involving more than one nasal subunit. Forehead flaps are often regarded as the best donor for nasal defect resurfacing because of its superior colour and texture match [19]. The donor scar produces substantial dissatisfaction in some patients which may require additional revisional surgery to achieve the desired aesthetic result [22]. From our series, flaps were almost 2.5 times more likely to require revisional surgery than grafts. Alam at al. [23] reported similar findings amongst grafts and flaps, which were risk factors for bleeding, infection and wound-healing complications. Interestingly, Patel et al. [18] recorded over half of complicated facial interpolated flaps after Mohs micrographic surgery occurred in the nasal and medial canthal region, resulting in nasal vestibular stenosis, saddle nose deformity, septal perforation and epiphora $[9,15,19]$. Unfortunately, formal documentation regarding the indications for revision in all cases is incomplete; however, anecdotally, the most common indications for ala revision surgery were a bulky flap causing either cosmetic deformity, airway obstruction or alar notching. The latter is a particularly challenging problem to treat, with multiple options available to help the reconstructive surgeon resolve the issue [24-26].
When nasal cartilage has been resected but the nasal mucosa is intact, cartilage grafts can be inset traditionally as a planned two-stage procedure. We did not find that cartilage grafting increased risk of unplanned revision surgery. This is in contrast to studies by Miller et al. [6] and Patel et al. [18] who reported an increased risk of complications in interpolated flaps with cartilage grafting. This may be the result of a relative small size $(n=16)$ for patients who underwent flap with cartilage reconstruction. In our series, we follow the advice of Menick [27] who suggests that a three-stage approach is less prone to complications. Driscoll [22] described equally good cosmetic and functional outcomes pedicled nasolabial or forehead flaps for composite nasal defects. Alar defects which are reconstructed using paramedian forehead flaps are generally twice the size of defects reconstructed with nasolabial flaps. Analysis of nasolabial and forehead flaps demonstrated that reconstructive outcomes were determined by the technical aspects of flap execution in contrast to the choice of flap [27].

A prosthesis was employed as a reconstructive modality only once in our cohort. Prosthesis maybe an appropriate reconstructive modality in lesions requiring total or near total amputation of the nose, especially in patients with significant comorbidities.

We acknowledge the limitations of our study. Reconstructive outcomes were measured in a single unit, potentially limiting external validity and generalizability with regard to reconstructive techniques and documentation. We did not specifically analyse comorbidities, smoking status or the use of antiplatelets/ anticoagulants- unlike Miller et al. [6].

We have demonstrated that ala and complex subunit lesions, squamous cell carcinoma and flap reconstruction were predictive indicators for revisional surgery in nasal reconstruction following MMS. Importantly, we showed that flap reconstruction for ala lesions significantly increased the risk of surgical revision. We have also demonstrated that lesions of the dorsum have a significantly reduced risk of surgical revision compared to other subunits, and interestingly, dorsum lesions were reconstructed with primary closure more than any other group. This study equips the resecting Mohs and/or reconstructive surgeons with the knowledge required to facilitate surgical planning, patient counselling and scheduling issues in patients with nasal skin cancer lesions.

Funding This study is funded by the Department of Plastic and Reconstructive Surgery, Norfolk and Norwich University Hospital NHS Foundation Trust.

Availability of data material Complete data transparency can be offered.

\section{Compliance with ethical standards}

Conflict of interest/competing interests Authors Tom W. Andrew, Jennifer J. Garioch, Penny E. Lovat and Marc D. Moncrieff declare that they have no conflict of interest. 
Ethics approval This is an observational study. The Clinical Audit and Improvement Department at the Norfolk and Norwich University Hospital registered the study (Ref: PLA-19-20_A03). The Research Ethics Committee has confirmed that no ethical approval is required.

Informed consent Informed consent was obtained from all individual participants included in the study

Patient consent Patients signed informed consent regarding publishing their data.

\section{Code availability N/A}

Open Access This article is licensed under a Creative Commons Attribution 4.0 International License, which permits use, sharing, adaptation, distribution and reproduction in any medium or format, as long as you give appropriate credit to the original author(s) and the source, provide a link to the Creative Commons licence, and indicate if changes were made. The images or other third party material in this article are included in the article's Creative Commons licence, unless indicated otherwise in a credit line to the material. If material is not included in the article's Creative Commons licence and your intended use is not permitted by statutory regulation or exceeds the permitted use, you will need to obtain permission directly from the copyright holder. To view a copy of this licence, visit http://creativecommons.org/licenses/by/4.0/.

\section{References}

1. Ridha H, Garioch JJ, Tan EK, Heaton MJ, Igali L, Moncrieff MD (2015) Intraoperative use of Mohs' surgery for the resection of major cutaneous head and neck cancer under general anaesthetic: initial experiences, efficiency and outcomes. J Plast Reconstr Aesthet Surg 68:1706-1712

2. British Association of Dermatologists. Service Guidance and Standards For Mohs Micrographic Surgery. https://www.bad.org. $\mathrm{uk} /$ shared $/$ get-file.. sh $x$ ?itemtype $=$ document $\& \mathrm{id}=6346$. Accessed 01 Sept 2020

3. Van Loo E, Mosterd K, Krekels GAM et al (2014) Surgical excision versus Mohs' micrographic surgery for basal cell carcinoma of the face: A randomisedclinical trial with 10 year follow-up. Eur J Cancer 50(17):3011-3020

4. Mosterd K, Krekels GA, Nieman FH et al (2008) Surgical excision versus Mohs' micrographic surgery for primary and recurrent basalcell carcinoma of the face: a prospective randomised controlled trial with 5-years' follow-up. Lancet Oncol 9:1149-1156

5. Muller FM, Dawe RS, Moseley H, Fleming CJ (2009) Randomized comparison of Mohs micrographic surgery and surgical excision for small nodular basal cell carcinoma: tissue-sparing outcome. Dermatol Surg 35:1349-1354

6. Miller MQ, David AP, McLean JE, Park SS, Christophel J (2018) Association of Mohs reconstructive surgery timing with postoperative complications. JAMA Facial Plast Surg 20(2):122-127

7. Moncrieff MD, Thompson JF, Quinn MJ, Stretch JR (2009) Reconstruction after wide excision of primary cutaneous melanomas: part I-the head and neck. Lancet Oncol 7:700-708

8. Rogers-Vizena CR, Lalonde DH, Menick FJ, Bentz ML (2015) Surgical Treatment and Reconstruction of Nonmelanoma Facial Skin Cancers. Plast Reconstr Surg 135(5):895e-908e
9. Burget GC, Menick FJ (1985) The subunit principle in nasal reconstruction. Plast Reconstr Surg 76(2):239-247

10. Rohrich RJ, Griffin JR, Ansari M, Beran SJ, Potter JK (2004) Nasal reconstruction - beyond aesthetic subunits: a 15-year review of 1334 cases. Plast Reconstr Surg: 1405-1416

11. Chi JJ, Rosenberg A, Hahn S et al (2018) Patient concerns about nasal reconstruction after mohs surgery and implications for shared decision making. JAMA Otolaryngol- Head Neck Surg 144(12): $1180-1181$

12. Rohrich RJ, Ahmad J (2011) Rhinoplasty. Plast Reconstr Surg 128(2):49e-73e

13. Burget GC, Menick FJ (1989) Nasal support and lining: the marriage of beauty and blood supply. Plast Reconstr Surg 84:189-203

14. Sclafani AP, Sclafani JA, Sclafani AM (2012) Successes, revisions, and postoperative complications in 446 Mohs defect repairs. Facial Plast Surg 28(3):358-366

15. Van Leeuwen AC, The A, Moolenburgh SE, De Haas ERM, Mureau MAM (2015) A retrospective review of reconstructive options and outcomes of 202 cases large facial Mohs micrographic surgical defects, based on the aesthetic unit involved. J Cutan Med Surg 19(6):580-587

16. Collins S, Dufresne R, Jellinek N (2008) The bilobed transposition flap for single-staged repair of large surgical defects involving the nasal ala. Dermatologic Surg 34(10):1379-1385

17. Rieger RA (1967) A local flap for repair of the nasal tip. Plast Reconstr Surg 40:147-149

18. Patel SA, Liu JJ, Murakami CS, Berg D, Akkina SR, Bhrany AD (2016) Complication rates in delayed reconstruction of the head and neck after Mohs micrographic surgery. JAMA Facial Plast Surg 18(5):340-346

19. Menick FJ (2013) Practical details of nasal reconstruction. Plast Reconstr Surg 131:613e-630e

20. Van Aalst JA, McCurry T, Wagner J (2003) Reconstructive considerations in the surgical management of melanoma. Surg Clin North Am 83(1): 197-230

21. Newlove T, Cook J (2013) Safety of staged interpolation flaps after Mohs micrographic surgery in an outpatient setting: a single-center experience. Dermatol Surg 39:1671-1682

22. Driscoll BP, Baker SR (2001) Reconstruction of nasal alar defects. Arch Facial Plast Surg 3(2):91-9

23. Alam M, Ibrahim O, Nodzenski M et al (2013) Adverse events associated with mohs micrographic surgery: Multicenter prospective cohort study of 20821 Cases at 23 Centers. JAMA Dermatology 149(12):1378-1385

24. Leach BC, Cook J (2009) Revisionary technique for alar rim notching: the stair-step flap. Dermatol Surg 35(10):1549-54

25. Jackson SM, Reisler T (2018) Nasal reconstruction: nasal alar rim notching deformity reconstruction with auricular composite chondrocutaneous graft. Eplasty 18(2018 Dec 20;18:ic25. eCollection 2018.):ic25. Available from: http://www.ncbi.nlm.nih. gov/pubmed/30643623

26. Regan C, Beynet D, Rotunda AM (2017) Alar notching and retraction. Dermatol Surg 43(4):587-590

27. Menick FJ (2002) A 10-year experience in nasal reconstruction with the three-stage forehead flap. Plast Reconstr Surg 109:1839 1855

Publisher's note Springer Nature remains neutral with regard to jurisdictional claims in published maps and institutional affiliations. 